\title{
Development of an online platform for experimental teaching in microeconomics
}

\author{
I. Barreda Tarrazona*; E. Camacho Cuena*, A. García Gallego*, M. Ginés Vilar*, A. \\ Jaramillo Gutiérrez*, S. López Ovejero*, S. Behnk*, A. Morone*, J. C. Pernías \\ Cerrillo*, G. Sabater Grande*, T. Jaber López*
}

* LEE \& Economics Department, Universitat Jaume I, Av. Vicente Sos Baynat, s/n, Castellón, España

\begin{abstract}
The instructors of the microeconomics courses at the University Jaume I in Castellón, Spain have created a group for educational innovation in microeconomics devoted to the introduction of experiment-based learning in the economics domain. The main goals of this project are to facilitate and to enrich student learning and to provide microeconomics teachers with useful materials to introduce experiment-based activities in their classroom. The methodology used is that of experimental economics: students participate in laboratory sessions where a computer program reproduces the main characteristics of the market structures studied in introductory and intermediate microeconomics. After the students interactions determine the outcome for each participant, the underlying theoretical model is solved and presented. Finally, observed and predicted outcomes are graphically compared and discussed. In order to facilitate this process, we developed a webpage in 2013 on which students and teachers can freely download instructions, software, theoretical solutions and data analysis examples corresponding to each experiment. Afterwards, we conducted a survey in order to evaluate the effectiveness of the classroom experiments in combination with the online platform. The results obtained from the questionnaire data show the effectiveness of our project. More than two thirds of the students considered these practices to be helpful for a better understanding of the course and confirmed a high demand for the online platform. 90\% stated that they would recommend the experimental lectures approach. We would like to share our materials with other universities that are considering these practices as part of their teaching processes so that they can benefit from our experience.
\end{abstract}

Keywords: Classroom Experiments; Microeconomics; Information Technologies

\section{Introduction}

During the academic course 2011-2012, the new degrees in Economics, Finance and Accounting as well as Business Administration were implemented at the University Jaume I in Castellón, Spain, and adapted to the European Higher Education Area. At the same time, a Group of Educational Innovation (GIE) in microeconomics was created that received funding and official recognition from the university to carry out educational innovation projects for the classroom. The first project promoted by the GIE was the implementation of experimental lessons in a computer laboratory in the modules related to the microeconomics field.

The main goal of this project is to facilitate and to improve the students' learning process by letting them explore and experience economic concepts on their own, so that they develop new skills and reach new learning objectives which were never systematically developed in previous programs. Moreover, lecturers are provided with guidance and tools for implementing this innovation in the classroom which can easily be used without previous experience in running didactical experiments.

\section{Laboratory classes}

The teaching methodology used is based on economic classes in the computer laboratory. These exercises are underpinned by the constructivist and interactive experimental approach and go back to Chamberlin (1948) and Smith (1962). By now, a variety of experiments have been developed regarding many aspects of economic settings, for instance regarding information cascades (Holt and Anderson, 1996), public good contributions (Holt and Laury, 1997) or monopolies (Oxoby, 2001). 
A limited variety of studies has investigated the effect of specific economic experiments on students' performance in particular tasks. For instance, the study of Frank (1997) found that participating in an experiment helped the students to better understand many aspects of the underlying problem but not all of them. Dickie (2006) also finds a positive effect of economic experiments in class. In his study, participation in several experiments was especially effective for the performance of top students. Durham et al. (2007) also confirm the positive effect of experiments on the students' performance and find different effects according to individual learning styles.

Students are active builders of their own knowledge during these classes, undertaking the role of a dynamic agent and being totally aware and responsible for their actions and their learning. On the other hand, most of the students still do not know the microeconomic theories which can predict their behaviour in the experiments before running them. This approach goes far beyond the classical learning-by-doing. In this way, they can build their own theories based on their decisions and observations of the experimental outcomes. After that, the students test the validity of their self-constructed concepts by comparing them with the formal mathematical theories which are presented in the module under different market conditions and explained later on.

The lessons start with a presentation of the market structures and the experimental rules followed by the preparation of the respective programs in the laboratory. Slides are used in order to organize all this information. Students have to get the program started on their own in order to become familiar with the software. The session continues with the participation of the students in an experimental market including the features of the market structures studied in the introductory modules of microeconomics (Pindyck \& Rubinfeld, 2009), for instance perfect competition, monopoly or duopoly. The markets are simulated with symmetric or asymmetric cost, with homogeneous or heterogeneous products. There are no explicit rules for the students about colluding or not with others during the experiment. Students are only informed that their main goal is to maximise their benefits and that they make their decisions on their own. During a pre-defined sequence of rounds, students make decisions about prices or quantities simultaneously or sequentially, depending on the market structure, for instance in the common Cournot, Bertrand or Stackelberg settings.

After finishing all market stages, the experiment ends and the lecturer solves the theoretical model of the market used in the experiment in front of the class. This part is particularly useful for the students as they acquire new theoretical and practical knowledge and combine this knowledge with what they learned before. At the end, the data obtained during the experiment is presented in the classroom using graphs. The students' aggregated decisions are compared with the previously calculated equilibrium magnitudes. In this way, the students can see the suitability of a particular theory for explaining a market situation they have just created.

Besides these learning advantages, carrying out the laboratory experiments is a challenge for the coordination of the course because it requires preparing many experiments with the corresponding instructions, theoretical solutions and experimental software including the coordination and monitoring of the students in the computer laboratory. Therefore, lecturers must be instructed to use Z-tree (Fischbacher, 2007), the software with which the market simulations were developed and programmed by the innovation group director, Iván Barreda Tarrazona. The lessons also require the lecturers' ability to react to differences in the convergence of the data to the theoretical predictions, an uncertainty that is unavoidable when using individual decision-making. 
Furthermore, it is a methodology which gives rise to questions and comments from the students which cannot always be predicted.

A challenge for students is that it requires their presence in the classroom in order to participate in the experiment. In order to motivate students to attend these classes, they are given the opportunity to solve a questionnaire regarding the observations they made during the experiments and the underlying theory, which accounts for $20 \%$ of the students' final mark in the course.

\section{Development of an online platform}

Information technologies are an efficient enhancement to the classical economic experiments (see, for instance, Cheung, 2008). In order to help with the coordination of the experimental lectures and to provide an easy access to material online for students and lecturers we developed a website, where instructions, software and examples of data analyses for a variety of classroom experiments can be found for downloading. The material is fully and freely accessible online after registration at "www.experimentosdeclase.com" and "www.lee.uji.es/experimentosdeclase". We use a creative commons license in terms of an equal share and not for commercial use. Thus, both students and lecturers are provided with an updated source to obtain all needed materials for the laboratory classes.

The website is a teaching tool designed to facilitate the teaching-learning process using new technologies. The attraction of new technologies and interactive environments in addition to the innovative methodology of didactic experiments are a promising motivation for students to participate actively in the course.

On the website we have taken into account the technical and visual requirements for an easy navigation, for instance the presence of the navigation menus, a clear design and the use of multimedia elements in order to motivate the reader. Furthermore, we implemented a frequently asked questions (FAQ) section so that students are able to find answers to the most common questions regarding the content of the website.

Moreover, we have considered didactic and pedagogical aspects (Cabero \& Gisbert, 2002), for instance the exposure to information by a brief and clear introduction, giving an idea of the topic, as well as the incorporation of conceptual maps to organise the contents, which gives the user the advantage of having all information summarized on a single page.

As a measure of the website's success we use a visit and download counter. A statistical service for websites is used to obtain reports regarding this data. Besides, we aim to create a list of lecturers who are using these programmes in their classes at different universities.

\section{Methods}

During the 2013-2014 academic year, we used four experimental practice groups in the Introduction to Microeconomics module (first year) and seven practice groups in the Microeconomics module (second year) at the University Jaume I. Altogether, this approach enabled over 3000 strategic behaviour experiences in different market settings during the academic year. In order to evaluate the use of the experimental practices and the online material as well as the students' satisfaction with this teaching methodology, 
they were given an anonymous questionnaire for evaluating their experience in these classes.

We have chosen the questionnaire as the most suitable evaluation method for the use of the online platform and the students' satisfaction, taking into account the main advantages pointed out by McKernan (1999) in relation with other information gathering methods. Some of these advantages are: the facility of evaluation and implementation, the opportunity to compare groups and individuals and the behaviour feedback, adequacy of resources, preparation of future sessions and quantifiable data.

We developed the questionnaire by firstly deciding on the information we wanted to obtain, evaluating the personal and temporary resources that we had, selecting the sample, using an appropriate wording for the questions and designing the questionnaire structure. Once the questionnaire was ready, it was handed out anonymously to 148 students who attended the experimental classes on a regular basis in different groups and with different lecturers, both in classes that took place in the morning and in the afternoon.

\section{Results}

Below, we describe the questions and the answer possibilities that were used in the questionnaire, combined with the graphical presentation of the obtained results. A summary of the aggregated results is presented at the end of this section.

In QUESTION 1 we asked: Considering what you have learned in the lectures and classes, how much did the laboratory classes help you in understanding the course? The possible answers to this question were: a lot, quite a lot, indifferent, a bit and nothing.

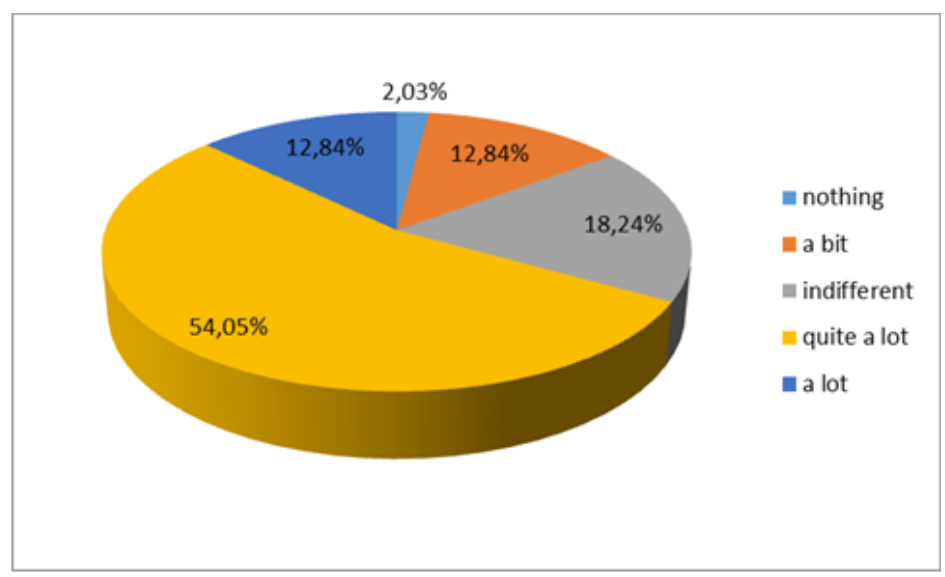

Figure 1. Understanding

QUESTION 2: Was it difficult for you to create a direct access to the program and to use it? The possible answers were: a lot, quite a lot, indifferent, a bit and nothing. 


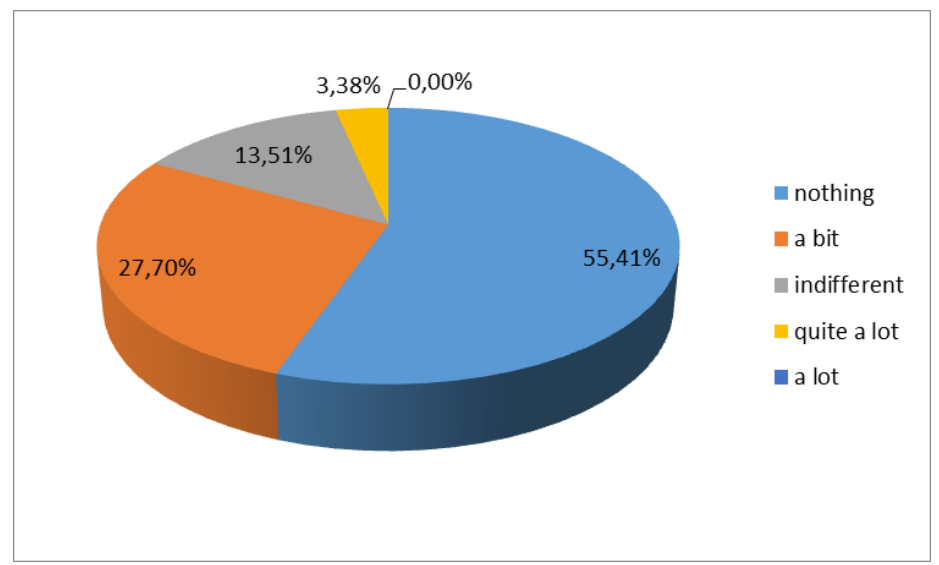

Figure 2. Usability of the program

QUESTION 3: Do the dynamics of the experiments motivate you to participate again? The possible answers were: a lot, quite a lot, indifferent, a bit and nothing.

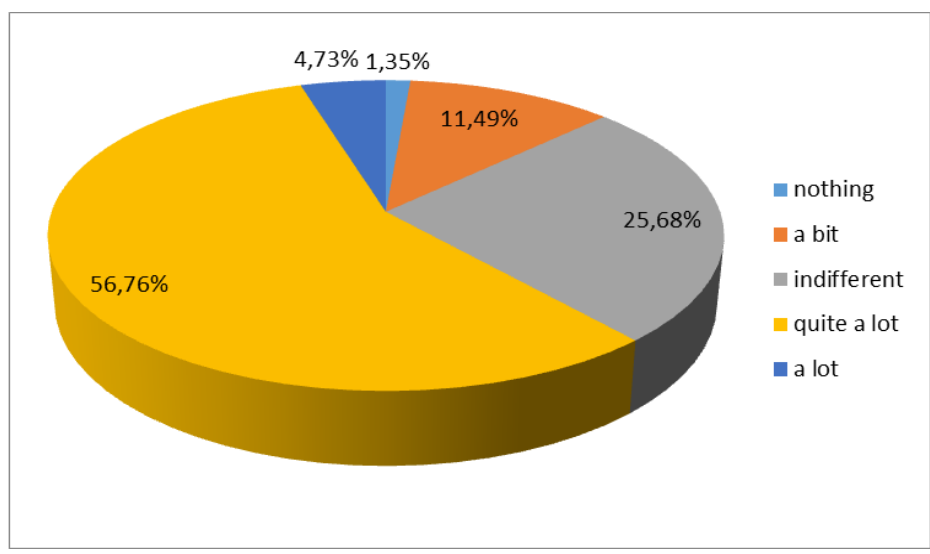

Figure 3. Motivation for participation

QUESTION 4: What do you think about the time you dedicated to the experimental decision-making in each session? The possible answers were: too much, adequate, insufficient.

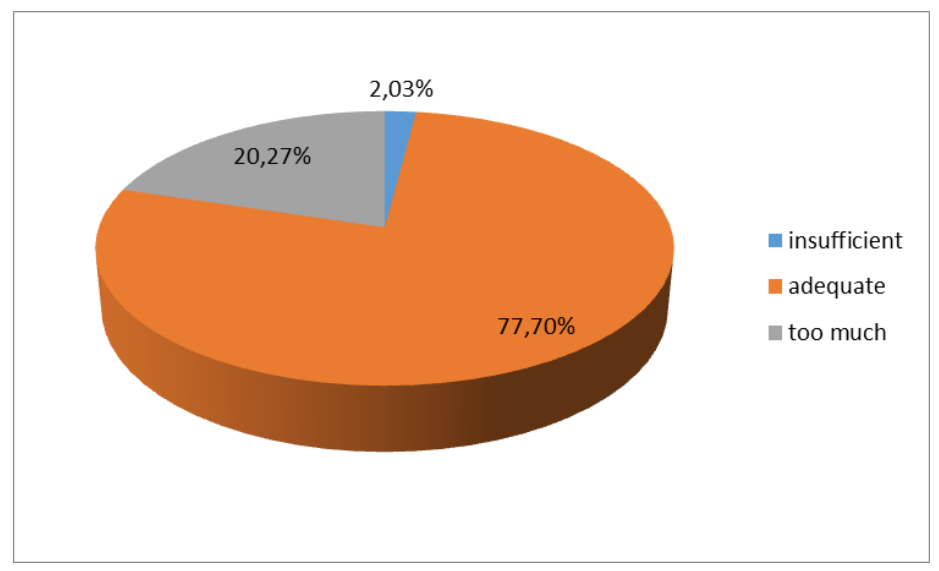

Figure 4. Dedicated time

QUESTION 5: Would you have found it useful to have access to a website during the course where you can view the various experiments that you participated in, in addition to the theoretical solutions and sample data? The possible answers were: a lot, quite a lot, indifferent, a bit and nothing. 


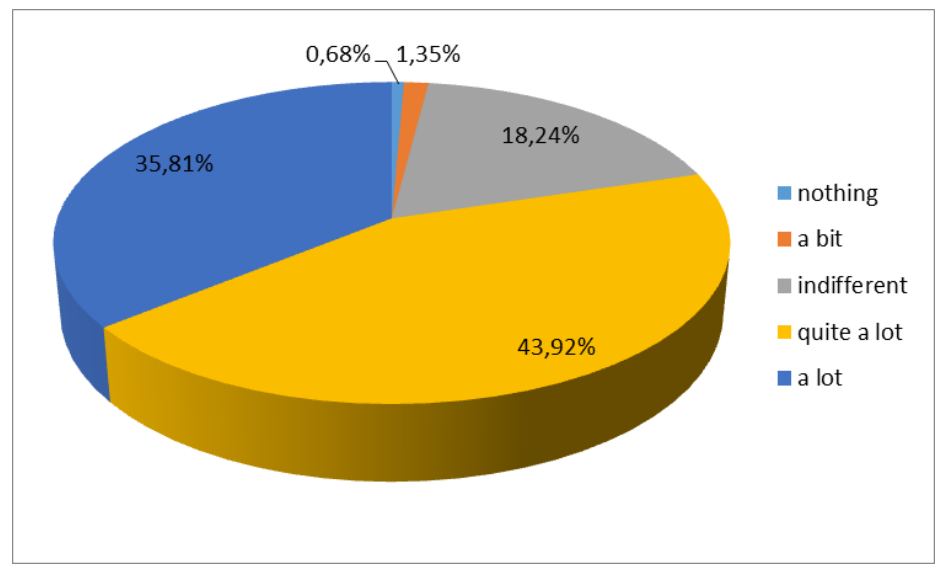

Figure 5. Usefulness of the website

QUESTION 6: Would you recommend to assist in the laboratory classes in the following course to a colleague? The possible answers were: yes and no.

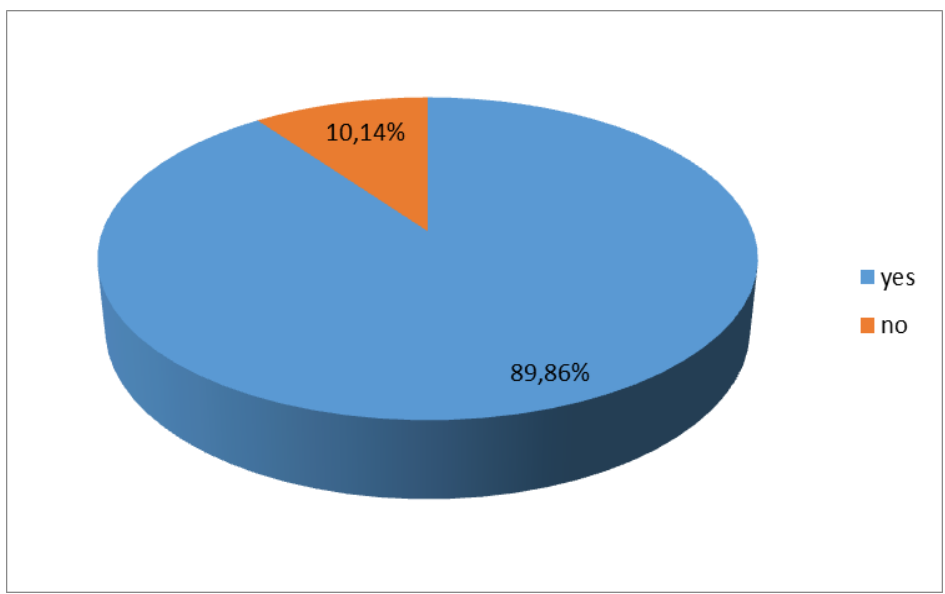

Figure 6. Recommendation

QUESTION 7: Do you think what you have learned in these classes will be useful in the future? The possible answers were: a lot, quite a lot, indifferent, a bit and nothing.

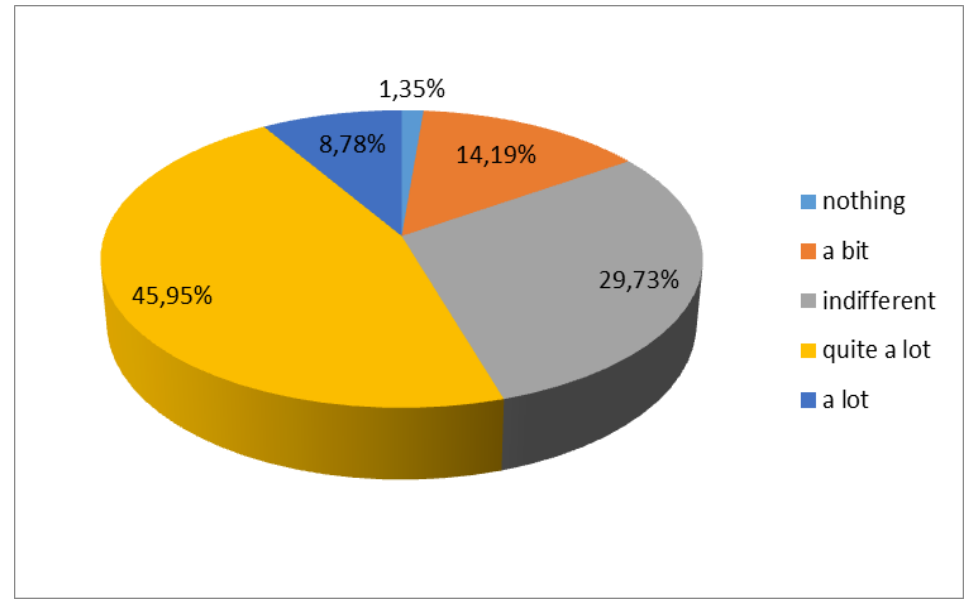

Figure 7. Usefulness of the classes 


\section{Discussion}

The results obtained from the questionnaire data show the effectiveness of our project. Altogether, more than two thirds of the participants stated that the laboratory classes helped them quite a lot and, respectively, a lot to understand the microeconomics courses in a better way using experiments. Their experience in the experimental practices encouraged the vast majority of the students to take an active part in future classes, thus the methodology used seems to motivate the students sufficiently. As a consequence, 9 out of 10 students would recommend the classes to their peers.

Their answers also confirmed the high demand for an online platform providing information and supplementary material regarding the experiments used in class. Regarding the question about the usefulness of a specific website for the experiment, $80 \%$ of the students think it would have helped "a lot" or "quite a lot", compared with another $18 \%$ who think it is indifferent and the other $2 \%$ who think it is not very useful. This indicates the importance of such an online platform and confirms again the success of the experimental classes. Lastly, more than half of the students in the survey stated that what they learned in these sessions is going to be useful in the future, which means that with this project we are enhancing some of the skills they think will allow them to better off their performances in the future.

Most of the students agreed with the available time to make decisions during the experiments and also with the balance between time dedicated to the game with the software, the mathematical solutions of the theoretical models and the descriptive analysis of data. But although almost $80 \%$ of the participants stated that the time they dedicated to the classes was adequate, still one fifth of them had the impression that the classes were too time-consuming. This can probably be due to the fact that the preparation of the computers and the programs for the market simulations are more time-consuming than the procedures in the standard microeconomic classes. Hence, although only $4 \%$ of the students declared that they had difficulties using the software, one aspect of future improvements of computer-based classroom experiments is the development of efficient processes to prepare the respective programs before and during the class.

\section{Conclusions}

We developed an online platform for classroom experiments in microeconomics, where instructions, software and examples of data analyses for a variety of experiments can be found for downloading. The material is fully accessible online after free registration at "www.experimentosdeclase.com" and "www.lee.uji.es/experimentosdeclase". It helps in understanding many subtle economic aspects which only a theoretical and expositive point of view could not do. After we started to run the experiments in the classroom and after we obtained the results from our survey, we have seen that the project achieves our objectives since it motivates students and facilitates the learning process. Particularly, more than two thirds of the students considered these practices to be helpful for a better understanding of the course and confirmed a high demand for the online platform. The vast majority stated that they would recommend the experimental lectures approach. This study sheds further light on the perception und effectiveness of classroom experiments and the respective platform in qualitative terms, but we do not compare the students' quantitative performance in terms of marks with and without the 
use of experiments and the online material. Another aspect of potential interest for future studies is how different student characteristics, such as personality traits or gender, interact with the efficacy of our approach in the individual learning process, based on the study of Durham et al. (2007). Finally, one of our main goals is to extend this tool to all Spanish-speaking lecturers who would like to offer this opportunity to their students. Our intention is to enhance all materials and to translate them into English in the near future.

\section{References}

Cabero, J. \& Gisbert, M. (2002). Materiales formativos multimedia en la red. Guía práctica para su diseño. Sevilla: Secretariado de Recursos Audiovisuales y Nuevas Tecnologías de la Universidad de Sevilla.

Chamberlin, E.H. (1948). An experimental imperfect market. Journal of Political Economy 56, 95-108.

Cheung, S.L. (2008). Using mobile phone messaging as a response medium in classroom experiments. Journal of Economic Education 39, 51-67.

Dickie, M. (2006). Do Classroom Experiments Increase Learning in Introductory Microeconomics? The Journal of Economic Education 37(3), 267-288.

Durham, Y., McKinnon, T. \& Schulman, C. (2007). Classroom experiments: not just fun and games. Economic Inquiry 45, 162-178.

Fischbacher, U. (2007). z-Tree: Zurich toolbox for ready-made economic experiments. Experimental Economics 10, 171-178.

Frank, B. (1997). The impact of classroom experiments on the learning of economics: an empirical investigation. Economic Inquiry 35(4), 763-769.

Holt, C.A. \& Anderson, L.R. (1996). Classroom games: Information cascades. Journal of Economic Perspectives 10(4), 187-193.

Holt, C.A. \& Laury, S.K. (1997). Classroom Games: Voluntary Provision of a Public Good. Journal of Economic Perspectives 11(4), 209-215.

McKernan, J. (1999). Investigación-acción y curriculum. Madrid: Morata.

Oxoby, R. (2001). A Monopoly Classroom Experiment. The Journal of Economic Education 32(2), 160-168.

Pindyck, R. S. \& Rubinfeld, D. L. (2009). Microeconomía. $7^{\text {a }}$ Edición, Madrid: Editorial Prentice Hall.

Smith, V.L. (1962). An experimental study of competitive market behavior. Journal of Political Economy 70, 111-137. 